\title{
LAS RELACIONES PÚBLICAS COMO HERRAMIENTA DE LA PROSPECTIVA
}

\section{PUBLIC RELATIONS AS A TOOL OF FORESIGHT}

David Caldevilla Domínguez: Profesor del Área de Comunicación en la Universidad Complutense de Madrid, la Universidad Europea de Madrid y Escuela Superior de Estudios de Relaciones Públicas

david.caldevilla@ccinf.ucm.es

\section{CURRÍCULUM VITAE}

Diplomado en Magisterio por la Universidad de Zaragoza (España), licenciado en Comunicación Audiovisual por la Universidad Complutense de Madrid (España). Profesor en la Facultad de Ciencias de la Información de la Universidad Complutense. Secretario General del Fórum Internacional de Comunicación y Relaciones Públicas (España) y autor de varios artículos en revistas universitarias. Director de Operaciones de Imagométrica, s.l. y ex directivo de varias firmas españolas del ámbito de la mercadotecnia.

\section{RESUMEN}

Desde unos postulados aparentemente no manipulativas, se crea una relación de confianza entre el emisor y el receptor cuando se trata de mensajes de claro carácter informacional. Es decir, en qué cosas creemos y por qué llegamos a creer en ellas. Es necesario que el receptor tenga una serie de filtros que le ayuden a discernir entre lo que es verosímil y lo que es veraz. 
Los publirrelacionistas somos, desgraciadamente, la última y única línea de defensa del hombre libre del siglo XXI, por lo que aceptamos nuestra Cruzada de liberación de aquellos que no disponen de acceso a estas herramientas y que son objetos pasivos de la manipulación por su desconocimiento.

\title{
PALABRAS CLAVE
}

Relación de confianza - Verosímil - Veraz - Publirrelacionistas - Cruzada

\begin{abstract}
Since apparently no one manipulative postulates, it creates a trust relationship between the sender and the receiver when it is clearly informational messages. Ergo, in which things we believe and why we come to believe in them. It's necessary that the receiver has a series of filters to help him to discern between what is credible and what is true.
\end{abstract}

The publirrelacionistas are, unfortunately, the last and only line of defense of free man of the XXI Century, therefore accept our Crusade release those who have no access to these tools and they are passive objects of manipulation by their ignorante.

\section{KEY WORDS}

Trust relationship - Credible - True - Publirrelacionistas - Crusade

\section{ÍNDICE}

1. Introducción

2. El futuro de la información 
3. La causa y consecuencia de la desinformación

4. Un adelantado: Harold Laswell

5. Receptor indefenso: confusión entre verosimilitud y veracidad

6. Un salto de gigante en la desinformación

7. Saber vender una venganza inadmisible

8. Destapar la farsa

9. Los Publirrelacionistas: última barrera defensiva del Mundo Libre

\section{TEXTO}

\section{Introducción}

El terrorismo internacional, ése que atenta contra todos aquellos valores que conforman los derechos inalienables del ser humano, reconocidos por la Organización de Naciones Unidas (los estamentos jurídicos más relevantes del planeta), sacude nuestras conciencias de profesionales en un área de la comunicación humana cada día más importante como lo es la informativa, convertida por otros en persuasiva.

El profesor doctor D. Luis Solano Fleta, primer catedrático en la materia de Relaciones Públicas en España, ha defendido el carácter informativo como la primordial, si no única, finalidad de las Relaciones Públicas; hoy por hoy, el hecho de negar su lado persuasivo supondría cerrar los ojos ante la nueva política mundial de los países democráticos y no democráticos que viven ya de vender imágenes a sus ciudadanos, los cuales pagan con su voto debido a la desinformación que los envide. 
Quizá nos hallamos ante una vuelta de tuerca de la historia en la que el Despotismo Ilustrado de mediados del siglo XVIII vuelve a refulgir: “Todo por el pueblo pero sin el pueblo". Las Relaciones Públicas corren serio riesgo de ser la mano ejecutora de esta tendencia neosecular.

Reflexionemos sobre este aspecto capital: De ser la información su objetivo final afirmaremos que las Relaciones Públicas obtienen carta de naturaleza a partir de una relación especial con el entorno de sus públicos, de manera que su validez camina pareja de su veracidad. Este concepto epistemológico nos llevará a afirmar taxativamente, al igual que hiciera la escolástica medieval que "para decir bien hay que decir verdad".

El terrorismo internacional, ése que atenta contra todos aquellos valores que conforman los derechos inalienables del ser humano, reconocidos por la Organización de Naciones Unidas (los estamentos jurídicos más relevantes del planeta), sacude nuestras conciencias de profesionales en un área de la comunicación humana cada día más importante como lo es la informativa, convertida por otros en persuasiva.

El profesor doctor D. Luis Solano Fleta, primer catedrático en la materia de Relaciones Públicas en España, ha defendido el carácter informativo como la primordial, si no única, finalidad de las Relaciones Públicas; hoy por hoy, el hecho de negar su lado persuasivo supondría cerrar los ojos ante la nueva política mundial de los países democráticos y no democráticos que viven ya de vender imágenes a sus ciudadanos, los cuales pagan con su voto debido a la desinformación que los envide.

Quizá nos hallamos ante una vuelta de tuerca de la historia en la que el Despotismo Ilustrado de mediados del siglo XVIII vuelve a refulgir: “Todo por el pueblo pero sin 
el pueblo". Las Relaciones Públicas corren serio riesgo de ser la mano ejecutora de esta tendencia neosecular.

Reflexionemos sobre este aspecto capital: De ser la información su objetivo final afirmaremos que las Relaciones Públicas obtienen carta de naturaleza a partir de una relación especial con el entorno de sus públicos, de manera que su validez camina pareja de su veracidad. Este concepto epistemológico nos llevará a afirmar taxativamente, al igual que hiciera la escolástica medieval que "para decir bien hay que decir verdad".

volver al primer apartado volver al principio del artículo volver al principio

\section{El futuro de la información}

En este estado de cosas queda claro que el futuro puede cambiar y ser modificado desde el presente ya que la prospectiva significa "ver hacia delante" y aunque no se puede estudiar el futuro ya que éste aún no existe, no es menos cierto que podemos pre-ver (ver con antelación) aquellos futuros que ofrecen más posibilidades de existencia para potenciarlos, erradicarlos o modificarlos según nuestra conciencia ética en cada momento y situación. Pero ¿qué sucede cuando esta "dirección" del futuro cae en manos de personas con valores "poco éticos" a nuestro recto entender?, quizá otros vean nuestros valores como subversivos o que atentan contra sus intereses...

Este aspecto manipulativo de la información entronca con la historia reciente de la Humanidad en sus más variados aspectos, eso sí, dentro del espectro político-social. Ahora es la llegada de revitalizar la componente ética y deontológica de los que manejan (o lo que es lo mismo manipulan, «mueven con las manos» en su etimo) ese valor precioso llamado información. 
Si la sociedad se nos presentara como un edificio en el que vivimos, la información constituiría su cemento amalgamador de pilares y ladrillos.

Desde el vasto campo de las Relaciones Públicas, a veces, los profesionales tanto de su docencia como de su aplicación mercantil, nos vemos abocados a plantearnos unas preguntas fundamentales en ambos campos:

¿Qué repercusiones tendrán en el futuro nuestras acciones de hoy?, ¿Somos las personas adecuadas para transmitir valores perennes?, ¿Qué ideas merecen perdurar? Si el presente era el futuro del pasado... ¿Quiénes diseñaron nuestro hoy, es decir, nuestra realidad, valores e ideas actuales?, ¿Podemos construir el futuro o al menos propuestas de éste?

volver al segundo apartado volver al principio del artículo volver al principio

\section{La causa y consecuencia de la desinformación}

En palabras del profesor colombiano Lucio Mauricio Henao Vélez: “El problema evoluciona sobre la imagen que se intenta como deseable, evitando caer en el fatalismo de lo probable". Entiéndase aquí por problema una cuestión cualquiera que afecte el orden de las cosas aún por venir. Y añade: “El aporte de la mirada prospectiva es la configuración de un grupo que declare transformable una problemática desde un contexto que ha sido diagnosticado y apropiado".

El maestro argentino Mario Bunge nos mostró en su método científico que el primordial y primigenio paso que hemos de dar a la hora de consolidar científicamente nuestro trabajo de investigación ha de ser "descubrir y plantear exactamente el problema". El ser humano es, desgraciadamente, demasiado 
fenomenológico para poder percibir los cúmulos de trampantojos que la vida cotidiana y sus actores principales nos deparan.

Un ejemplo clarificador de mis palabras sería la común experiencia que todos hemos padecido alguna vez al tratar de arrancar nuestro automóvil por la mañana y no lograrlo. Nos preguntan, ¿Por qué has llegado tarde al trabajo? y respondemos habitualmente Porque no arrancaba mi auto. Lógico error: Hemos confundido el efecto por la causa de la situación. La verdadera respuesta sería: Porque el motor de arranque está sucio, o porque la batería se había agotado, o porque el carburador se había humedecido... es decir, la carencia de información correcta (y formación personal en ese saber en particular) nos hace tomar los efectos por las causas.

Quien nos proporcione contenidos (léase información) verosímil y si es a la par veraz, mejor, sobre las circunstancias concurrentes tendrá comprada nuestra actitud.

Dijo una vez Abraham Lincoln que se podía engañar a muchos poco tiempo, a algunos más tiempo y a unos pocos mucho tiempo, pero que nunca se podría engañar a muchos siempre. A mayor formación del pueblo, menor capacidad de ser manipulados y mayor garantía de control de los poderes que dicen representarnos. volver al tercer apartado volver al principio del artículo volver al principio

\section{Un adelantado: Harold Laswell}

Como la naturaleza de la comunicación se desglosa en dos caras de una misma realidad, un qué o contenido y un cómo o forma (a su vez mediatizados por el canal, el destinatario, el tipo de contenidos y un largo etcétera que mejor comprenderemos aplicando el paradigma de Harold Laswell) hemos de tener en cuenta esta doble articulación a la hora de afrontar su análisis. 
Si modelizamos el paradigma de Harold Laswell (quién, dice qué, a quién, por qué canal, con qué efecto), resultaría que la retroalimentación del sistema es el eje central de nuestro trabajo.

Recordemos que la principal función de las Relaciones Públicas no sería actuar o hacer, sino, más sutilmente (no hay publicidad más dañina que la ofrecida bajo la fórmula de la inocente información) hacer que otros hagan. Éste y no otro es el fin último de las Relaciones Públicas.

Para mejor entender el paradigma recordemos algunos de los hechos que destacan en la vida de $\mathrm{H}$. Laswell.

Harold Laswell fue un destacado cientifista y político estadounidense. Entre 1940 y 1945 trabajó en la Biblioteca del Congreso de los Estados Unidos, como Jefe de la División Experimental para el Estudio de las Comunicaciones en Tiempo de Guerra. De 1946 a 1970, trabajó en la Universidad de Yale. Su interés por la propaganda política lo llevó a preocuparse por los fenómenos de la comunicación. Fue uno de los más influyentes activistas de la necesidad de desarrollar investigación en materia de comunicación y cumplió un papel importante en poner en marcha la institucionalización de esos estudios. Por ello se le identifica como uno de los padres fundadores de la investigación en el área. Formuló el conocido e influyente Modelo de las 5 preguntas: ¿Quién, dice qué, a quien, por qué canal, y con qué efecto? Aunque este modelo da por sentado el hecho de los efectos de los medios de comunicación, y aunque se asocia su nombre a una concepción de efectos poderosos de los medios, en verdad sus escritos evolucionaron hasta admitir la importancia de las predisposiciones y de las singularidades culturales en la recepción de los mensajes. Otro rasgo de su obra fue la aplicación de los conceptos del psicoanalista Sigmund Freud. 
Es notable que la Opinión Pública haya de ser manipulada y los estudios a tal efecto avancen más deprisa a partir de las Guerras (en especial las mundiales) con una abigarrada mezcla de conductismo, psicosociología (recordemos la técnica de los hombres de 4 minutos de Franklin. D. Roosvelt en 1942) y psicoanálisis.

Los medios de comunicación para masas interpretarían aquí el papel, imprescindible por otra parte en la Aldea Global de Marshall Mac Luhan, de altavoces de la conciencia común impregnada de los tintes propios de cada sistema y ocasión, al albur, algunas veces de los designios de un grupo de interés que nada o poco tienen que ver con los intereses del gran grupo llamado sociedad.

Nota: (La codificación / descodificación se presupone siempre correcta, es decir, no aberrante

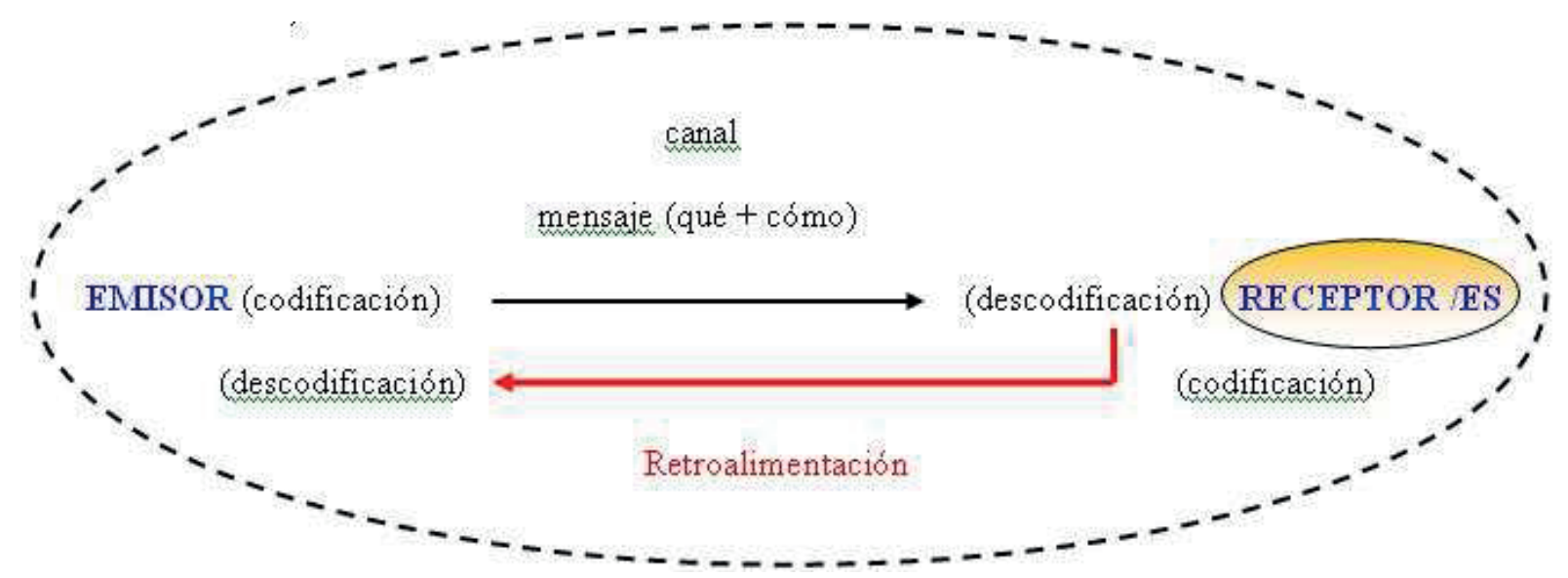

ÁREA DE LA OPINIÓN PÚBLICA por adición de Receptores agrupados ya sea por propia voluntad y consentimiento (ejemplo: un partido político, un equipo deportivo...), como por "etiquetado" desde el Emisor sin voluntad ni conciencia de pertenencia (ejemplo: Las audiencias de un programa de TV, el hecho de calzar una talla 42 de zapatos...). 


\section{Receptor indefenso: Confusión entre verosimilitud y veracidad}

A mayor formación, cultura y conocimientos, más alto ubicaremos el listón de exigencias que deberán cumplir los manipuladores de querer desarrollar su trabajo, y una vez dominado el campo de estos conocimientos (es decir, de los contenidos de las comunicaciones) los publirrelacionistas deberán marcar con su saber las estrategias de defensa en cuanto a las formas en que nos es ofrecida, como la manzana del Edén, esta información mediatizada.

Al igual que el ojo humano no distingue como fijas las fotografías pasadas ante él con una cadencia superior a 12 unidades por segundo, y les da un sentido unitario que imita el movimiento (este es el principio fisiológico del cine), los actos comunicativos dirigidos hacia el modelado de la Opinión Pública pasan las más de las veces ante nuestro análisis como inocentes datos de afán informativo para las masas ávidas de llenar el vacío comunicativo que existe sobre ciertos temas que los propios medios, y esto es lo más importante, han creado como de interés para toda la Comunidad. Es la profecía que se cumple a sí misma. Se dice "sucedió tal cosa", se analiza, se dan los porqués y se concluye como evidente la situación actual o status quo imperante. En ese mismo statu quo es donde hallan caldo de cultivo las justificaciones más extremas y las soluciones, a veces, más delirantes, que se muestran como única salida o derrotero de la singladura de las decisiones gubernamentales, de marcado tinte sectarista.

Una vez más lo verosímil se impone a lo veraz.

Un conocido "guía de opinión" español, presentador de un noticiario de máxima audiencia a mediodía, concluye el programa informativo diario con un latiguillo que se ha hecho célebre entre todas las capas sociales del país: "Así son las cosas y así se las hemos contado". ¿Cabe mayor argucia comunicativa? 


\section{Un salto de gigante en la desinformación}

Pongamos un ejemplo: La llegada del hombre a la Luna. Han surgido últimamente muchas voces discrepantes sobre la presencia de los astronautas norteamericanos en la superficie de nuestro satélite ya que posee todos los condimentos para ser considerado un guiso de la cocina de la Agencia Central de Inteligencia Norteamericana «C.I.A.».

En 1963 el posteriormente asesinado presidente J. F. Kennedy "promete" a los estadounidenses que vengará la afrenta del Sputnik (Revolución en ruso) haciendo que un hijo de las Barras y Estrellas camine sobre la Luna antes de que la década finalice. La profecía comienza a tomar cuerpo.

En verano de 1969 (un año antes de que la década concluya ya que, contra el erróneo criterio popular y muy extendido, las décadas no comienzan por los años en 0 y terminan en los 9, sino que las décadas comienzan por uno y terminan con el año que cambia la decena, por tanto la década de los sesenta comenzó en 1961 y concluyó en 1970 ambos inclusive) Neil Alden Armstrong holla la superficie lunar junto con el coronel Edwin E. Aldrin mientras Michael Collins lo contempla desde los mandos del módulo Águila. La profecía se cumplió.

Curioso: Los soviéticos jamás pisaron la Luna, pese a que su programa espacial Vostok fue el primero que colocó en órbita un satélite lunar y el primero que logró hacer llegar una sonda no tripulada (octubre de 1968). Asimismo el primer satélite a Venus y a Marte fueron suyos y en la década de los 70 y 80 construyó las primeras estaciones habitadas allende la atmósfera terrestre: Las extintas Salyut y Mir, lo cual provocó que los estadounidenses crearan la Skylab. Tras estos hitos es algo complicado de entender como el coloso del Cosmos renunció a izar la hoz y el martillo sobre el polvo selenita. Nikita S. Kruschev (Presidente desde 1958 hasta 
1964) o su sucesor Leonidas Brezhnev (1964-1982) quizá se conformaban con las gigantografías (fotografías de tamaño descomunal presentes en las manifestaciones o colgadas de los edificios) de la época de Stalin, renunciando complacientes al impacto mundial que podía causar la medalla de plata de esta carrera a 400.000 kilómetros del Kremlim. El sacrificio de Laika quedó sin ansiada recompensa.

La prueba irrefutable de este viaje sólo comparable con los de Cristóbal Colón o Luis Váez de Torres (descubridor de Australia, aunque no la llegara a pisar) sería tan sencilla como enfocar con un telescopio de gran potencia (el Hubble sería el más indicado) hacia la bandera "que ondeó" incluso sin atmósfera, en aquella ocasión. Nunca se ha hecho aduciendo razones espurias.

Por supuesto que estas líneas no pretenden poner en duda ese "pequeño paso para un hombre pero un salto de gigante para la Humanidad", sino que intentaban crear en el auditorio presente la reflexión sobre qué es aquello que conforma nuestras creencias y por qué motivos lo aceptamos como verdad. Convencido estoy de que el Sr. Armstrong paseo su traje de neopreno por esa inhóspita aún zona cero de los sueños estadounidenses y por ende mundiales.

Oportuno es que a esta inicial reflexión, tras pedir disculpas por la pequeña trampa sobre la veracidad del primer viaje a la Luna que me ha servido de ejemplo introductorio, sea aliñada con otros aspectos extraídos de la actualidad más candente.

La generación de imágenes patrióticas suele ser recurso habitual para mitigar catástrofes o biombo tras el cual se enmascaran acciones con destinos distintos a los que inicialmente se han lanzado como mensaje a las masas. $Y$ en eso no hay duda que ciertos países están a la cabeza de esta clasificación. 
Si el periodismo nos ha enseñado, gracias a Rudyard Kipling, que tiene cinco grandes amigos (las famosas Ws sajonas):

Quién

Cómo

Cuándo

Dónde

Por qué

Las Relaciones Públicas nos plantean sólo dos, pero mucho más clarificadoras que sus antecesoras en el cetro del interés:

Para qué

Quién sufraga esto (o lo que es lo mismo, quién sale ganando con esto y le merece la pena el dispendio económico)

Este pragmatismo poco romántico ha de ser entendido enmarcado en la praxis propia de la comunicación persuasiva, es decir, la que está más enfocada a la obtención de resultados. Su validez caminaría pareja de sus logros.

En este estado de cosas pretendo sean entendidas mis palabras. 


\section{Saber vender una venganza inadmisible}

Tras el 11 de septiembre de 1973, en que el Palacio de la Moneda de Santiago de Chile fue bombardeado y sus defensores muertos, nunca el mundo había sentido tan intensamente la llegada de este día como efeméride de un acto catastrófico hasta que otro 11 de Septiembre, esta vez ya en el siglo XXI, va a arrebatar el testigo de esta carrera de la sinrazón. Las Torres Gemelas de Nueva York caen ante el impacto de dos aviones de pasajeros y el Pentágono (sede del cuartel general del primer y mejor ejército del mundo) sufre el ataque de un misil u otro avión comercial según sean las fuentes consultadas.

La venganza es mía, se arroga Dios en el Eclesiastés, y aunque hoy esté mal visto para los católicos el ojo por ojo y diente por diente (la famosa ley del Talión inscrita en la línea 216 el código sumerio de Hammurabi), hemos de recordar que la historia está plagada de hechos, las más de las veces luctuosos, derivados de este primitivo instinto del hombre como animal de la naturaleza. El problema es vender esa venganza (justa o no, las Relaciones Públicas pueden permitirse el lujo de no emitir juicios epistemológicos aunque sí lógicos) dentro de los cauces socialmente admisibles y políticamente correctos.

Muchas de las veces que se ha hablado de la razón final de la descolonización de India por parte de Gran Bretaña se aduce que la política de no acción o desobediencia civil del "Alma Grande" Gandhi fue la causa última y primordial. Por mi parte, creo que la verdad respondió a una razón mucho menos romántica. Fueron, más bien, las amenazantes tropas imperiales japonesas llamando a la puerta de India desde Birmania las que forzaron a los Británicos a pactar con el Partido del Congreso hindú una salida pacífica tras la guerra a cambio de su no alineación del bando nipón y así mantener las bases indias como sustento de una guerra de difícil pronóstico en Asia en aquel momento ya que había en liza más de un millón y medio de soldados 
indígenas en la contienda. Gandhi y Nehru fueron encarcelados entre 1942 y 1944 por si acaso. Así, llegado el 1947 (dos años después de la paz) Lord Louis Mountbatten (nacido Battenberg) partió de su palacio virreinal hacia la Metrópoli.

Irónico que las tropas imperiales japonesas, que habían sojuzgado pueblos enteros (China, Corea, Birmania, Vietnam...) bajo el estandarte de la libertad por cuyo motivo afirmaban haber declarado la guerra a las potencias colonizadoras de Asia (Francia, Gran Bretaña, Holanda, Portugal...) lograran su propósito tras perder atómicamente la guerra.

El año siguiente, 1948, fue testigo de una de las actividades más febriles que se recuerdan de la guerra fría pero que pasó ante los ojos de la Humanidad sin levantar polvareda ni hacer notar su presencia pese a lo crucial de su significado: La C.I.A. crea en unión y por orden del Departamento de Estado (equivalente en gran medida a nuestro Ministerio de Interior) la Oficina de la Diplomacia Pública(Public Diplomacy) como servicio de Propaganda cuya labor principal sería sobornar a líderes de opinión como periodistas, intelectuales, dirigentes políticos de países amigos. Años más tarde se desplaza esta actividad del Departamento de Estado, eminentemente civil, al Departamento de Defensa. La administración Bush padre pretendió ampliar el campo de actividades de los servicios de Propaganda a la población norteamericana aún y a costa de transgredir la Ley de Autorizaciones de Relaciones Foráneas (Foreign Relations Authorizations Act) de 1972. A raíz de los incalificables hechos del 11 de Septiembre de 2001 el Pentágono creó la Oficina para la Influencia Estratégica (Office for the strategic Influence) bajo el mando del General Simon Pete Worden antiguo jefe del Comando espacial Estadounidense. Este organismo se articula en los Programas de Información Internacional (International Informations Programs) del Departamento de Estado y que comprende las transmisiones de la radio La Voz de Estados Unidos (Voice of America) a través del Grupo Militar de Información Internacional (International Military Information 
Group) del coronal Brad Ward. La finalidad de este Organismo de reciente creación, pese a que desde 1997 se había tratado de someter a opinión el mejor engranaje en el sistema de una Oficina de similares características, es "manipular las Opiniones Públicas y los Gobiernos Occidentales".

Ha pasado la era de «Hill \& Knoulton», la mayor consultora de Relaciones Públicas del mundo, con sede en Estados Unidos, pese a su éxito a la hora de crear para la Administración del Presidente Bush padre el clima prebélico de la guerra del Golfo en 1992, en especial con el magistral detalle del robo de las incubadoras "presenciado" por la hija del Embajador Kuwaití en Estados Unidos o el de no menor importancia relativo a un ave petroleada en las costas del Golfo que resultó ser una grabación procedente del hundimiento de un petrolero en Alaska. El hecho de involucrar a los militares supone que esta vez más que nunca la cosa va muy en serio.

\section{Destapar la farsa}

Demóstenes, el gran demagogo de la Atenas del siglo IV a. d. C., refulge de entre las sombras del olvido y creo que nuestra labor como Publirrelacionistas es desenmascarar la verdad de la mentira, la manipulación de la información y en resumen servir de último bastión frente a la aldea global regida por cualquier Gran Hermano.

Por lo tanto, el planteamiento de las Relaciones Públicas que propongo reside en centrar nuestros enfoques y nuestros posteriores estudios al ámbito de la practicidad democrática y circunscribir nuestras acciones, salvo la esclavitud del error, a la búsqueda de esa entente cordial entre los públicos receptores y los emisores. Desenmarañemos la paja del grano: Es nuestro deber moral. 
Las invocaciones a la legalidad occidental del mundo libre, a Dios y a la apropiación de nombres son otras de las constantes de la Propaganda mundial. Hagamos un breve repaso.

En cuanto a nombres, queda claro que América es un continente completo desde el Ártico hasta el Antártico, con casi mil millones de habitantes. Hoy en día la palabra americano equivale a ciudadano de un solo país de los más de 30 que componen el continente y archipiélagos adyacentes. Es curioso como el país más poderoso que nunca haya existido sobre la faz de la Tierra carece de nombre: Estados es un término jurídico, Unidos un adjetivo común, de Norteamérica designa un lugar de ubicación geográfica.

Los judíos creen que dar nombre a las cosas es dotarlas de alma y existencia. Esa idea ha pasado desde esta cultura teocrática al mundo actual.

En lo referente a la legalidad del llamado Mundo Occidental Libre es a veces curioso el contrasentido que produce: En 1898, los Estados Unidos de Norteamérica declaran la guerra a España a favor de la independencia de los territorios extraeuropeos de dicha potencia. Para ello favorece los movimientos independentistas de estos territorios (en especial Cuba y Filipinas ya que Puerto Rico carecía de este tipo de movimientos al igual que las islas de la Polinesia y Micronesia Españolas en el Pacífico) y finalmente manda a sus tropas regulares tras generar un incidente que causa víctimas de su propio país «El acorazado de segunda clase Maine». Cuba en agradecimiento a sus esfuerzos designa un territorio de su costa como concesión a este país (Cuba con España no tuvo estatuto de Colonia, sino de territorio de pleno derecho) en un nuevo colonialismo. Este tratado de cesión de soberanía sobre Guantánamo caducaría a los 100 años salvo firma de nuevo acuerdo entre ambos países. En 1999 expiraba este plazo y el Gobierno cubano decidió no prorrogar dicho 
acuerdo. El vínculo de la legalidad se ha roto. Este dato es desconocido en España y afirmo sin temor que en el resto del mundo también.

Propaganda es un gerundivo latino del verbo propago (difundir) que traducido vendría a significar "lo que ha de ser difundido o conocido". Surge de la labor del Papa Urbano VIII quien en 1622 creó la Congregatio de Propaganda Fide (Congregación para la Divulgación de la Fe) para que elaborara un corpus teórico dedicado a adoctrinar a los misioneros católicos en sus labores evangelizadoras. Desde este momento, quedó claro que el flujo de la propaganda era unidireccional: De arriba hacia abajo.

Si en la historia universal ha habido una lucha fundamental, ésta no ha sido otra que la de la habida para la consecución de los medios de comunicación como herramienta para llegar a los económicos y sus gemelos, los del poder político, verdadera cara de la, más citada que comprendida, lucha de clases del siglo XIX.

Los medios de comunicación para masas no han hecho sino tecnologizar el talante difusor de los agitadores, de los políticos, de los demagogos, de los salvadores, de los tiranos, de los interesados, en suma de cualesquiera que han tenido una motivación para llevar "el agua pública al molino de su voluntad particular", si se me permite tal aplicación a esta popular sentencia.

De nada serviría hablar de "lo que hay que hacer" (término correspondiente a otro gerundivo latino que podría traducirse por "agenda") sin decir en qué consistiría esta actitud vital ante el futuro. 


\section{Los Publirrelacionistas: última barrera defensiva del Mundo Libre}

En Agosto de 1978 en México D. F., el llamado Acuerdo de México se convirtió en el hecho fundacional en lo referente a la función de los publirrelacionistas. La F.I.A.R.P. «Federación Interamericana de Asociaciones de Relaciones Públicas» propuso una definición de Relaciones Públicas con la que todos los miembros de la Comunidad publirrelacionística creo que estamos de acuerdo: “El ejercicio profesional de las Relaciones Públicas exige una acción planeada con apoyo de la investigación en la comunicación sistemática y en la participación programada, para elevar el nivel de entendimiento, solidaridad y colaboración entre una entidad pública o privada y los grupos sociales a ella vinculados, en un proceso de integración de intereses legítimos, para promover su desarrollo recíproco y el de la comunidad a la que pertenece".

Para que esta definición sea perfecta deberíamos andar el camino que nos separa de un necesario enfoque ético. Es hora de incluir este precepto necesario en estos albores del tercer milenio.

Si no anduviéramos ese camino, nos moveríamos siempre dentro de los parámetros que definen las Relaciones Públicas como ese conjunto de saberes que marcan la separación y sirven a su vez de linde entre los "contenidos para servir a" de los que se emplean "para servirse de". Es esa labor y no otra la que se propone desde la perspectiva de la creación de imágenes comunes ya que la prospectiva nos ayudará a saber cuál es el futuro al que tendemos sin estar sujetos a la esclavitud del fatalismo ni caer en la anarquía del azar.

Los Publirrelacionistas somos la última y puede que también la única línea de defensa del Mundo libre, es decir, del formado por personas informadas que emiten sus opiniones a tenor de la veracidad de los datos obtenidos y su completitud. 
La Escuela Iberoamericana de Relaciones Públicas ha de ser sostenida sobre estos pilares.

Os invito, queridos Colegas de intereses e idioma, a vivir este sueño. 